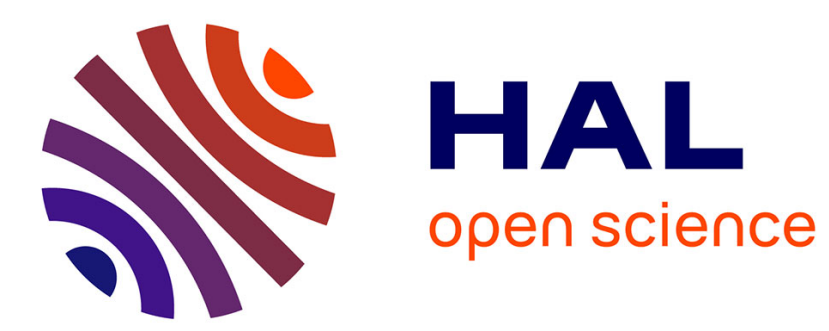

\title{
ELECTRIDES AND ALKALIDES - COMPARISON WITH METAL SOLUTIONS
}

\author{
J. Dye
}

\section{To cite this version:}

J. Dye. ELECTRIDES AND ALKALIDES - COMPARISON WITH METAL SOLUTIONS. Journal de Physique IV Proceedings, 1991, 01 (C5), pp.C5-259-C5-282. 10.1051/jp4:1991531 . jpa-00250655

HAL Id: jpa-00250655

https://hal.science/jpa-00250655

Submitted on 1 Jan 1991

HAL is a multi-disciplinary open access archive for the deposit and dissemination of scientific research documents, whether they are published or not. The documents may come from teaching and research institutions in France or abroad, or from public or private research centers.
L'archive ouverte pluridisciplinaire HAL, est destinée au dépôt et à la diffusion de documents scientifiques de niveau recherche, publiés ou non, émanant des établissements d'enseignement et de recherche français ou étrangers, des laboratoires publics ou privés. 


\title{
ELECTRIDES AND ALKALIDES - COMPARISON WITH METAL SOLUTIONS
}

J.L. DYE

Department of Chemistry and Center for Fundamental Materials Research, Michigan State University, East Lansing, Michigan 48824, U.S.A.

\begin{abstract}
The similarities between species in ammonia, amine and ether solutions of the alkali metals and in crystalline alkalides and electrides is striking. In solution we can identify the species $\mathrm{M}^{+}$solv, $\mathrm{e}^{-}$solv, $\mathrm{M}^{-}, \mathrm{M}^{+} \cdot \mathrm{e}^{-}$, $" \mathrm{e}_{2}="$, and at high concentrations, $\mathrm{e}^{-}$conduction. In alkalides, electrides and mixed systems, species analogous to each of these can be found, in addition to alkali metal anion dimers, $\mathbf{M}^{=}$solv, and chains, $\left(\mathbf{M}^{\mathrm{n}-}\right)_{n}$. Since the last Colloque Weyl we have determined the crystal structures and properties of 30 alkalides and 4 electrides. Correlation of structures and properties can now be made and will be discussed. A potentially rich area of investigation is the solution and liquid-state chemistry of alkalides and electrides. It is likely that the compound $\mathrm{Li}\left(\mathrm{CH}_{3} \mathrm{NH}_{2}\right)_{4}$, studied by Sienko and others some time ago in both the liquid (metallic) state and the solid (semiconductor?) state, is an electride. Analogous alkalides, such as $\mathrm{Li}^{+}\left(\mathrm{H}_{2} \mathrm{NCH}_{2} \mathrm{CH}_{2} \mathrm{NH}_{2}\right)_{2} \mathrm{Na}^{-}$, $\mathrm{Li}^{+}\left(\mathrm{CH}_{3} \mathrm{NH}_{2}\right)_{4} \mathrm{Na}^{-}, \mathrm{Li}^{+}\left(\mathrm{C}_{2} \mathrm{H}_{5} \mathrm{NH}_{2}\right)_{4} \mathrm{Na}^{-}$can be prepared and it appears that other alkali metal anions can be used instead of $\mathrm{Na}^{-}$. The solubility and stability of alkalides and electrides dissolved in dimethyl ether suggest that these would be excellent systems for the study of the properties of alkali metal solutions.
\end{abstract}

\section{1 - Introduction}

Electrides and alkalides have much in common with alkali metal solutions in ammonia, amines, polyethers and other solvents. Not only are crystalline electrides and alkalides synthesized from metal solutions, but many of the same species that are used to explain solution properties are also present in the ionic crystals.[1] This paper reviews the evidence for various species in solution and uses the crystal structures and properties of electrides and alkalides to identify similar species in the solid state. The variety of packing geometries of the complexed cations (and in alkalides of the alkali metal anions) results in a number of interesting phenomena. For example, electrides exhibit electron localization, delocalization, spin-pairing and antiferromagnetism [2]; and various alkalides contain separated alkali metal anions, cation-anion pairs, anion dimers and chains of anions. 
The complexation of $\mathrm{Li}^{+}$by the primary amines ethylenediamine (EDA), methylamine $\left(\mathrm{MeNH}_{2}\right)$ and ethylamine $\left(\mathrm{EtNH}_{2}\right)$ provides new liquid and solid electrides and alkalides whose properties warrant further study. Finally, a case is made for new studies of alkali metal solutions (with cation complexants) in the aprotic solvent dimethyl ether $\left(\mathrm{Me}_{2} \mathrm{O}\right)$ and for the use of such solutions for inorganic, organometallic and organic synthesis.

\section{2 - Species in Metal Solutions}

\section{1 - Solvated Electrons}

The identification of the species present in metal solutions has intrigued scientists for well over 100 years and, even now, there is by no means universal agreement about the nature of these species. Everyone agrees that dilute metal solutions in ammonia and liquids subjected to ionizing radiation contain solvated electrons, but whether these electrons are trapped in cavities or exist as "solvated solvent anions" or "negative solvent clusters" is still debated. The weight of experimental and theoretical evidence for cavity formation is substantial and the species $e^{-}$solv will be assumed in this paper to be an electron that is self-trapped in a cavity with short-range solvent dipole orientation and long-range polarization.

\section{2 - Solvated Cations}

The nature of the charge-balancing cation in metal solutions is not in dispute. The solvation free energy (free enthalpy in the European notation) of the cation to form $\mathrm{M}^{+}$solv is the major driving force for metal solubilization. This limits metal solubilities in most solvents and places the small polar molecule, $\mathrm{NH}_{3}$, in a special position. Except for $\mathrm{MeNH}_{2}$ and $\mathrm{EtNH}_{2}$, which can form concentrated solutions of lithium, ammonia is the only solvent that can form concentrated alkali metal solutions.[3] Fortunately, the thermodynamically allowed decomposition to form hydrogen, which prevents stable solution formation in water, alcohol and other oxidizing solvents, does not occur rapidly in pure ammonia, presumably because of the endothermic barrier to the initiation reaction

$$
\mathrm{e}^{-} \text {solv }+\mathrm{NH}_{3} \rightleftharpoons \mathrm{H}+\mathrm{NH}_{2}^{-}
$$

Replacement of the primary solvation free energy of the cation in other solvents by the free energy of complexation with a cryptand, crown ether or similar complexant is the driving force for enhanced solubility of the alkali metals when a suitable complexant is present.[4-6]

\section{3 - Ion Pairs or "Monomers"}

Although we frequently refer to individual ionic species such as $\mathrm{M}^{+}$solv and $\mathrm{e}^{-}$solv in metal solutions, the low dielectric constants of the solvents used result in substantial ionic aggregation. For example, a $10^{-2} \mathrm{M}$. solution of $\mathrm{Na}$ in $\mathrm{NH}_{3}$ at $-37{ }^{\circ} \mathrm{C}$ contains approximately $45 \%$ of a neutral species, probably the ion-pair $\mathrm{Na}^{+} . \mathrm{e}^{-} \cdot \cdot[7-8]$ In a solvent with a lower dielectric constant, such as $\mathrm{Me}_{2} \mathrm{O}$ or tetrahydrofuran (THF), at $10^{-2} \mathrm{M}$. the ions are virtually all present as ion pairs. 
Thus, except at very high dilutions, $e^{-}$solv is not really free but is coupled to a solvated cation.

In amine and ether solvents, the lifetime of the neutral species, " $M$ ", is long enough to observe it directly by EPR studies of the hyperfine coupling of $\mathrm{e}^{-}$solv to the metal cation. $[9,10]$ The "percent atomic character" that results is strongly dependent on the solvent and the temperature.[11] Ethylamine-ammonia mixtures of potassium show a decreasing coupling constant as the ammonia content decreases. An increase in temperature causes an increase in the percent atomic character, reaching values as high as $24 \%$ for $\mathrm{Cs}$ in $\mathrm{EtNH}_{2}$ at $800^{\circ} \mathrm{C}$. I proposed a simple explanation of this behavior some years ago that still seems valid.[13] According to this picture, the ion-pair between $\mathrm{e}^{-}$solv and $\mathrm{M}^{+}$solv can range from a solvent-separated or solvent-shared species in $\mathrm{NH}_{3}$ and/or at low temperatures to a "contact" ion-pair in a less polar solvent and/or at higher temperatures. The range of behavior is continuous as the center of electron charge density approaches that of the solvated cation. Collapse to a solvated atom is an extreme case that would lead to loss of ion-dipole solvation energy for both the cation and the electron. Thus, a compromise is reached that balances the Coulomb attraction between $\mathrm{M}^{+}$and $\mathrm{e}^{-}$and the ion-dipole interactions of both ions with the solvent.

\section{4 - Electron Pairs}

One of the remaining mysteries of metal-ammonia solutions is the formation of the paired electron species $" \mathrm{e}_{2}=$ ". The quotation marks are included to remind us that we do not know the role played by the cation in this pairing phenomenon. All the alkali metals show the decrease in molar susceptibility that accompanies the spin-pairing process.[14] Indeed, the extent of pairing seems to be relatively independent of the metal. That the phenomenon is significant is indicated by the fact that a $10^{-1} \mathrm{M}$. solution of $\mathrm{Na}$ in $\mathrm{NH}_{3}$ has only $30 \%$ of the paramagnetism expected for independent electron spins. Information about the extent of spin-pairing in other solvents is scarce and, in any event, would be obscured by the formation of alkali metal anions. After discovery of the latter species in amine solvents, it was attractive to consider that $\mathbf{M}^{-}$formation in ammonia might be responsible for the observed electron spin-pairing. But there is simply no evidence for "genuine" alkali metal anions in metal-ammonia solutions. By extending the concept of ion-pairing to include clusters such as $\mathrm{e}^{-\cdot} \cdot \mathrm{M}^{+} \cdot \mathrm{e}^{-}$and $\left(\mathrm{M}^{+} \cdot \mathrm{e}^{-}\right)_{2}$, one can rationalize the spin-pairing; but the high concentrations required and the long lifetimes necessary require more stabilization than would be provided by simple Coulomb attraction. For the present, we must hide our ignorance behind the symbol " $e_{2}=$ " with the understanding that this species is strongly ion-paired with $\mathrm{M}^{+}$.

\section{5 - Alkali Metal Anions}

The species M-, a "genuine" alkali metal anion with two electrons in the outer $s$ orbital, was first proposed for metal-ammonia solutions $[15,16]$ and later for metal-amine and metal-ether solutions [17] on the basis of optical spectra. The assignment in the latter two types of solutions was soon verified, with alkali metal NMR spectra making it clear that it was not merely a cluster of solvated cations and solvated electrons.[18,19] All properties, spectra, conductivities, 
magnetic susceptibilities and NMR spectra were in accord with this assignment.[20] A solution of sodium in $\mathrm{MeNH}_{2}$ or EDA clearly consisted largely of $\mathrm{Na}^{+}$solv and $\mathrm{Na}^{-}$solv. Other metals showed that $\mathrm{M}^{-}$is in equilibrium with solvated electrons and cations [6] according to

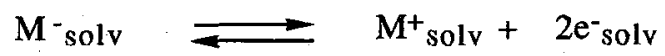

No conclusive evidence has been found for $\mathrm{Li}^{-}$in solution, presumably because the solvation energy of $\mathrm{Li}^{+}$is great enough to drive reaction (2) completely to the right in all solvents that can dissolve lithium.

\section{6 - Conduction Electrons}

A great deal of attention has been directed in previous Colloques Weyl to the non-metal to metal transition and to metallic compounds between alkali (or alkaline earth or $\mathrm{Eu}$ or $\mathrm{Yb}$ ) metals and ammonia. Lithium in methylamine at high (>15 mole percent metal) concentrations is the only known metallic solution aside from those formed by metals in ammonia.[21-23] Clearly, conduction electrons must be considered as important species at high concentrations.

A simple phenomenological picture can be used to rationalize electron delocalization in concentrated metal-ammonia solutions. The fully solvated electron probably requires at least 4 ammonia molecules in its primary solvation sheath, and, in dilute solutions, it probably has considerably more than this number around it. The cations (except $\mathrm{Li}^{+}$) require $6 \mathrm{NH}_{3}$ molecules in their primary coordination sphere. The solvation free energy of $\mathrm{e}^{-}$solv is considerably less than that of $\mathrm{M}^{+}$solv. At 10 mole percent metal (MPM), only $4 \mathrm{NH}_{3}$ molecules are available for electron solvation. By about 4 MPM, the average electronelectron overlap is great enough to meet the Mott criterion for metallization.[24,25] Interestingly the optical reflectivity in this concentration region shows the presence of both solvated electron and conduction electrons.[26] Thus, in the concentration region below and somewhat above that which leads to metallic behavior, there is a competition between electron localization and delocalization. As the solution becomes more concentrated, the availability of ammonia for solvation (localization) decreases and the metallic character increases.

\section{7 - Complexed Cations}

The addition of strong complexants for the alkali metals, crown ethers, 1 , cryptands, 2, methylated aza-crown ethers, 3, etc. provides a new kind of species, $M^{+} L_{n}$, the complexed cation, (in which $n$ is 1 or 2 ) to our arsenal of species in metal solutions.[4-6] This has the effect of markedly increasing the total

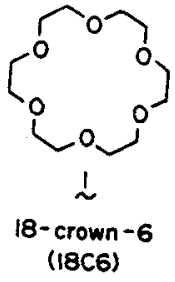

(18C6)

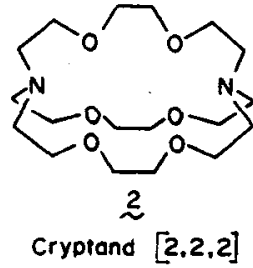

(C222)

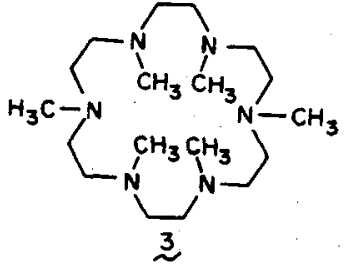

Hexamethy! Hexacycien (HMHCY) 
concentration of dissolved metal via the equilibria

$$
\begin{aligned}
& \mathrm{M}(\mathrm{s}) \rightleftharpoons \mathrm{M}^{+}{ }_{\text {solv }}+\mathrm{e}_{\text {solv }} \\
& \mathrm{M}(\mathrm{s}) \rightleftharpoons \mathrm{M}^{+} \text {solv }+\mathrm{M}_{\text {solv }} \\
& \mathrm{M}^{+} \text {solv }+\mathrm{nL} \rightleftharpoons\left(\mathrm{M}^{+} \mathrm{L}_{\mathrm{n}}\right)_{\text {solv }}
\end{aligned}
$$

If the equilibrium constant for Reaction (5) is large, say $10^{5}$ or greater (not uncommon in these solvents), the effect on metal solubility is remarkable. For example, none of the alkali metals dissolve to a detectable extent in $\mathrm{Me}_{2} \mathrm{O}$. But they are very soluble $(>0.5 \mathrm{M}$.) in the presence of a suitable cryptand or crown ether.

Another useful feature of complexants is that they can permit control of the stoichiometry in solution. The complexant tends to shift Reactions (2), (3) and (4) to the right. In the presence of at least two moles of complexant per mole of metal, the overall process may be represented by

$$
\mathrm{M}(\mathrm{s})+\mathrm{nL} \rightleftharpoons \mathrm{M}^{+} \mathrm{L}_{\mathrm{n}}+\mathrm{e}^{-} \text {solv }
$$

provided Reaction (2) is not too far to the left. On the other hand, if enough metal is present, the overall process may be described by

$$
2 \mathrm{M}(\mathrm{s})+\mathrm{nL} \rightleftharpoons \mathrm{M}^{+} \mathrm{L}_{\mathrm{n}}+\mathrm{M}^{-}
$$

or if two different metals, $M_{a}$ and $M_{b}$, are present, by

$$
\mathrm{M}_{\mathrm{a}}(\mathrm{s})+\mathrm{M}_{\mathrm{b}}(\mathrm{s})+\mathrm{nL} \rightleftharpoons \mathrm{M}_{\mathrm{a}}{ }^{+} \mathrm{L}_{\mathrm{n}}+\mathrm{M}_{\mathrm{b}}
$$

Obviously, depending on the affinity of $\mathrm{M}_{\mathrm{a}}+$ for the complexant and the stability of $\mathrm{M}_{\mathrm{b}}{ }^{-}$, various mixtures are possible. Presumably also, the various other equilibria common to metal solutions can lead to ion-pairs, electron-pairs, etc. However, such complications have not yet been investigated.

\section{3 - Species in Electrides and Alkalides}

\section{1 - Crystal Structures Of Alkalides}

The crystal structures of 20 alkalides have now been determined in our laboratory and the results are either published or will be soon. Table 1 summarizes the key features of these structures. Structure determinations of 10 other alkalides have also been made, but the analyses are not yet complete. The positions of the alkali metal species can be directly determined from the electron density maps. The structures of the complexed cations are so similar to those of model compounds that do not contain $\mathrm{M}^{-}$that there can be no doubt about the identification of $M^{+} L_{n}$ in the alkalides. The other alkali metal species must therefore be $M^{-}$or $\left(M+\mathrm{e}^{-}\right)$or $\left(\mathrm{M}^{+}+2 \mathrm{e}^{-}\right)$. The optical,[42-44] NMR [45-51] and EPR 
TABLE 1. ALKALIDE - ELECTRIDE STRUCTURAL DATA

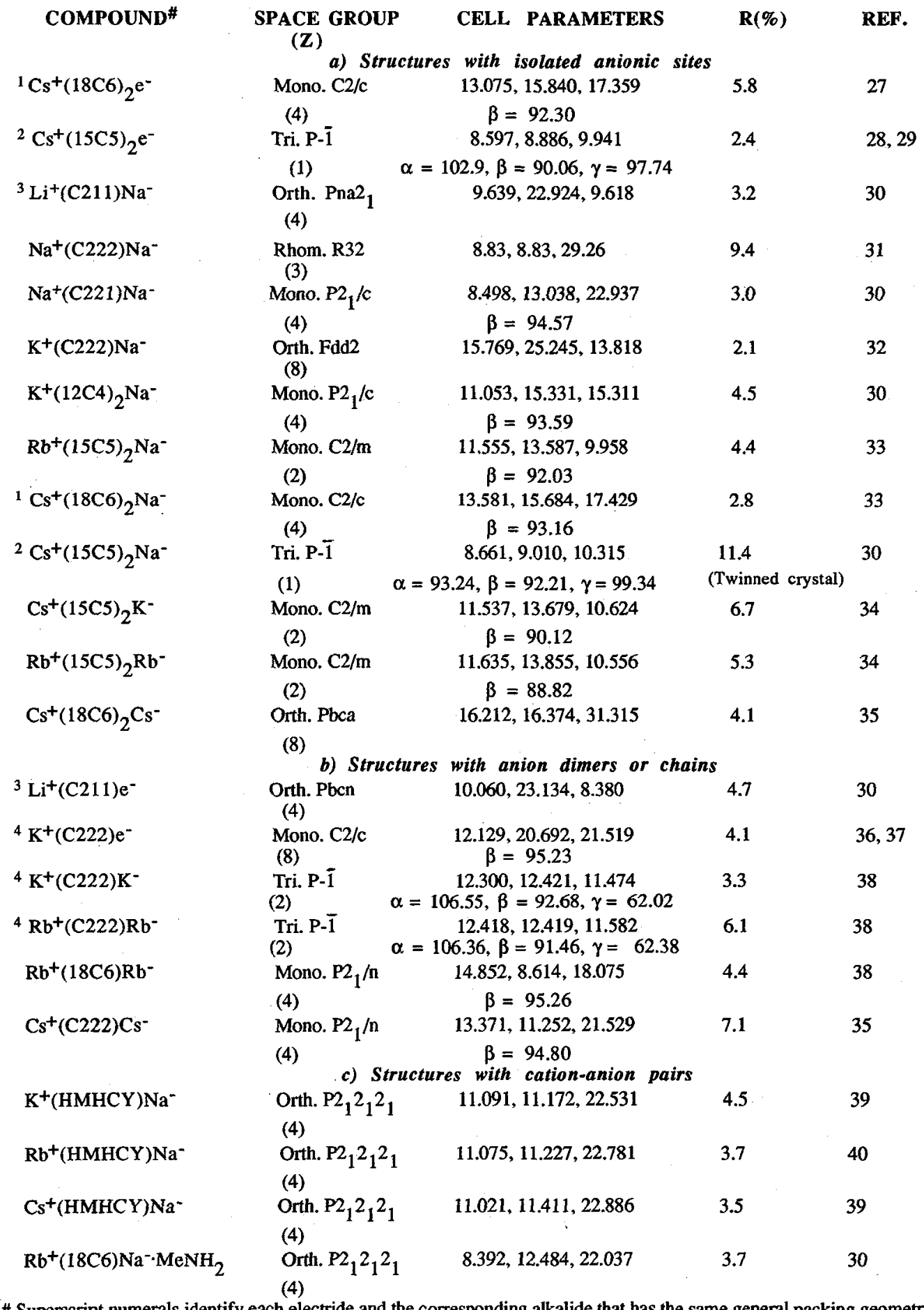

\# Superscript numerals identify each electride and the corresponding alkalide that has the same general packing geometry. 
spectra show that $M^{-}$is present in all cases. In mixed alkalides that contain $\mathrm{M}_{\mathrm{a}} \mathrm{L}^{+} \mathrm{n}$ and $\mathrm{M}_{\mathrm{b}}{ }^{-}$, the structure can be used to identify $\mathrm{M}_{\mathrm{a}}$ and $\mathrm{M}_{\mathrm{b}}$. All known structures, except that of the "parent" alkalide, $\mathrm{Na}^{+}(\mathrm{C} 222) \mathrm{Na}^{-}$, have been determined since the time of Colloque Weyl VI, so our understanding of the nature of alkalides has expanded considerably since that time. The structures may be classified according to the relation of $\mathrm{M}^{-}$to neighboring species. Each type will be separately considered.

\subsection{1 - Separated Anions}

Many alkalides crystallize in such a way that the anions occupy sites that are relatively isolated from each other and in which $\mathrm{M}_{\mathbf{a}}{ }^{+}$and $\mathrm{Mb}_{\mathbf{b}}{ }^{-}$are separated by a portion of the complexant molecule. The latter situation always occurs when the cation is encapsulated by a cryptand molecule or when it is sandwiched between two complexant molecules $(n=2)$. In such cases, we can identify the effective radius of $\mathrm{M}_{b}$ - by assigning van der Waals (v.d.W.) radii to $C, H, O$ and $N$ and an ionic radius to $\mathrm{M}_{\mathrm{a}}{ }^{+}$.

The anionic site is surrounded by the $\mathrm{H}$-atoms of $-\mathrm{CH}_{2}$ - groups of the complexant. Thus, a minimum radius of $\mathbf{M}^{-}$can be established as the nearest $\mathbf{M}^{-}$ to $\mathrm{H}$ distance, minus $1.1 \mathrm{~A}$, the v.d.W. radius of $\mathrm{H}$ in $-\mathrm{CH}_{2}-$ We expect, however, that two factors operate to make the effective radius of $\mathrm{M}^{-}$larger:

1. The $-\mathrm{O}-\mathrm{CH}_{2}$ - group is rather polar, with an effective partial charge on $\mathrm{O}$ as high as -0.6 a.u. [52] This means that the $-\mathrm{C}-\mathrm{H}$ bond is polarized in such a way that the $\mathrm{H}$ atom is rather positive. This will decrease the effective v.d.W. radius of $H$ and increase the attraction between $\mathrm{M}^{-}$and $H$.

2. The alkali metal anions are very polarizable so that distortions from spherical symmetry and the penetration of $H$ into the outer regions of $\mathbf{M}^{-}$ are likely.

By using the average distance between $\mathrm{M}^{-}$and the first shell of surrounding $\mathrm{H}$ atoms we arrive at effective radii of alkali metal anions.[38] The minimum and effective radii obtained from a number of structures are given in Table 2.

The effect of anionic radius on the packing is illustrated in Figure 1 for the alkalides $\mathrm{Cs}^{+}(18 \mathrm{C} 6)_{2} \mathrm{Na}^{-}$and $\mathrm{Cs}^{+}(18 \mathrm{C} 6)_{2} \mathrm{Cs}^{-} .[1,53]$ In the former case, $\mathrm{Na}^{-}$is small enough to fit easily into the space provided by close-packing of 8 crown ether sandwiched cations, $\mathrm{Cs}^{+}(18 \mathrm{C} 6)_{2}$. The geometry is dictated by the "goodness of fit" of the complexed cations as they tend to fill space. By contrast, $\mathrm{Cs}^{-}$is large enough that it cannot fit into the space provided by cationic packing, and the structure is "opened up" as a result. This gives rise to a rather unusual coordination of $\mathrm{Cs}^{-}$. Each anion has, as nearest neighbors, seven sandwiched cations and two other $\mathrm{Cs}^{-}$anions. Yet the $\mathrm{Cs}^{-}$to $\mathrm{Cs}^{-}$spacing along the resulting chain $(8.86 \AA)$ is large enough that the anions are not touching (v.d.W. diameter = $7.0 \AA) .[35]$

\subsection{2 - Ion Pairs}

What happens when the complexant does not completely encapsulate the cation? Such is the case with HMHCY,3, as the complexant.[39] The methyl groups on the nitrogens are too bulky to permit sandwich formation around $\mathrm{M}^{+}$, as can occur with the crown ethers. Yet the molecule is not sufficiently large and flexible to completely "wrap around" the cation. As a result, the cation is exposed 
on one face. Similarly, although 18-crown-6 can form stable sandwich complexes with $\mathrm{Cs}^{+}$, the other alkali cations are too small to permit this. Therefore, one or two faces of the cation are exposed and available to interact with either the solvent or with $\mathrm{M}^{-}$.

TABLE 2. MINIMUM AND EFFECTIVE RADII (IN §) OF ALKALI METAL ANIONS a

\section{ALKALIDE}

Sodides (Natrides)
$\mathrm{K}^{+}(\mathrm{C} 222) \mathrm{Na}^{-}$
$\mathrm{Cs}^{+}(18 \mathrm{C} 6)_{2} \mathrm{Na}^{-}$
$\mathrm{Rb}^{+}(15 \mathrm{C} 5)_{2} \mathrm{Na}^{-}$
$\mathrm{K}^{+}(\mathrm{HMHCY}) \mathrm{Na}^{-}$
$\mathrm{Cs}^{+}(\mathrm{HMHCY}) \mathrm{Na}^{-}$
$\mathrm{Na}^{+}(\mathrm{C} 221) \mathrm{Na}^{-}$
$\mathrm{K}^{+}(12 \mathrm{C} 4) \mathrm{Na}_{2}^{-}$
$\mathrm{Cs}^{+}(15 \mathrm{C} 5)_{2} \mathrm{Na}^{-}$

Potassides(Kalides)

$\mathrm{K}^{+}(\mathrm{C} 222) \mathrm{K}^{-}$

$\mathrm{Cs}^{+}(15 \mathrm{C} 5)_{2} \mathrm{~K}^{-}$

\section{Rubidides}

$\mathrm{Rb}^{+}(\mathrm{C} 222) \mathrm{Rb}^{-}$

$\mathrm{Rb}^{+}(18 \mathrm{C} 6) \mathrm{Rb}^{-}$

$\mathrm{Rb}^{+}(15 \mathrm{C} 5)_{2} \mathrm{Rb}^{-}$

Cesides

$$
\begin{aligned}
& \mathrm{Cs}^{+}(\mathrm{C} 222) \mathrm{Cs}^{-} \\
& \mathrm{Cs}^{+}(18 \mathrm{C} 6)_{2} \mathrm{Cs}^{-}
\end{aligned}
$$

RADIUS OF $\mathbf{M}^{-}$

MINIMUM
2.55
2.34
2.60
2.48
2.35
2.75
2.39
2.64

2.94

2.77

3.00

2.99

2.64

3.17

EFFECTIVE
$2.73(14)$
$2.64(16)$
$2.89(16)$
$2.77(10)$
$2.79(8)$
$2.91(10)$
$2.65(10)$
$2.83(10)$

$3.12(10)$

$3.14(16)$

$3.21(14)$

$3.23(9)$

$3.06(16)$

$3.50(15)$

$3.46(15)$
3.30

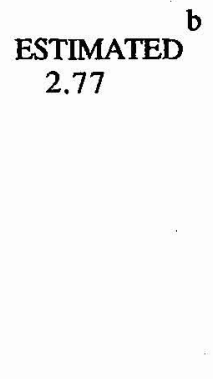

3.60

a The minimum radius is the distance between the center of the anion and its nearest hydrogen, minus $1.2 \AA$, the van der Waals, radius of hydrogen. The effective radius is the distance averaged over the number of adjacent hydrogens given in parentheses.

b The estimated radius is the interatomic spacing in the metal minus the radius of the cation. [17]

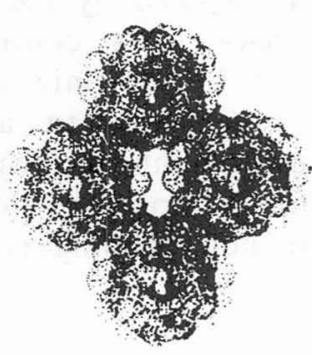

(a)

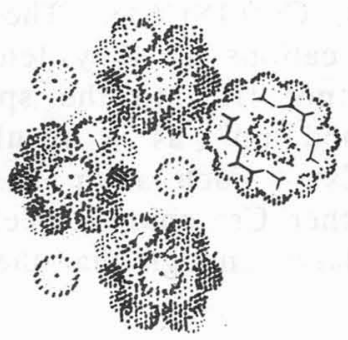

(b)

Figure 1. - Diagram of portions of the structures of (a) $\mathrm{Cs}^{+}(18 \mathrm{C} 6)_{2} \mathrm{Na}^{-}$and (b) $\mathrm{Cs}^{+}(18 \mathrm{C} 6)_{2} \mathrm{Cs}^{-}$. Shown are the Van der Waals surfaces of the complexant. The small circles in $b$ represent the locations of $\mathrm{Cs}^{-}$but are not to scale. 
The presence of direct cation-anion pairs is evident in the structures of $\mathrm{Ma}_{\mathrm{a}}+(\mathrm{HMHCY}) \mathrm{Na}^{-}$, in which $\mathrm{M}_{\mathrm{a}}^{+}=\mathrm{K}^{+}, \mathrm{Rb}^{+}$or $\mathrm{Cs}^{+}$. Figure 2 shows the ionpair structure in $\mathrm{K}^{+}\left(\mathrm{HMHCY}^{-} \mathrm{Na}^{-}\right.$. In this case, the cation is pulled far enough into the complexant that there is a gap of 0.25 to $0.45 \AA$ between the surfaces of $\mathrm{K}^{+}$and $\mathrm{Na}^{-}$. In $\mathrm{Cs}^{+}(\mathrm{HMHCY}) \mathrm{Na}^{-}$, however, the cation and anion are essentially in contact. Remarkably, the properties, such as optical and NMR spectra, show no evidence of charge transfer from $\mathrm{Na}^{-}$to $\mathrm{Cs}^{+}$, in spite of their close proximity.

It has proven difficult to crystallize $\mathrm{M}_{\mathrm{a}}{ }^{+} \mathrm{LM}_{\mathrm{b}^{-}}$, in which $\mathrm{L}$ is a crown ether with $n=1$. Recent indications are that solvent tends to be included in the structure, probably to provide an additional ligand for $\mathrm{M}^{+} .[30]$ The exception, $\mathrm{Rb}^{+}\left(18 \mathrm{C}^{6}\right) \mathrm{Rb}^{-}$, will be considered later.

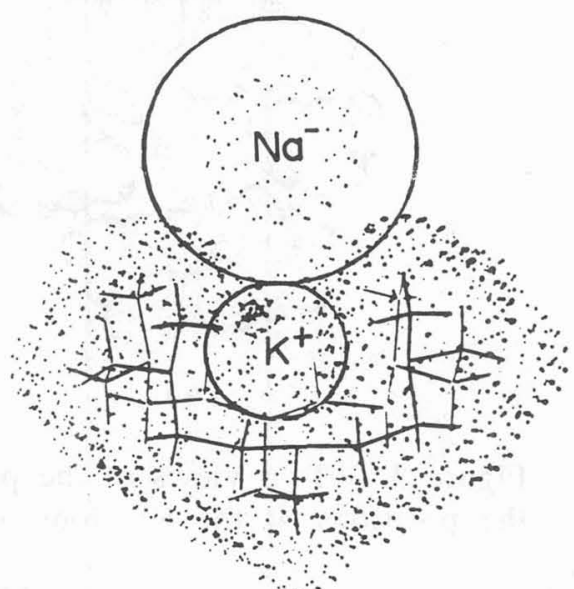

Figure 2. - Cation-anion packing in $\mathrm{K}^{+}(\mathrm{HMHCY}) \mathrm{Na}^{-}$, showing the formation of a contact ion-pair.

\subsection{3 - Dimers and Chains}

The structures of $\mathrm{K}^{+}(\mathrm{C} 222) \mathrm{K}-$ and $\mathrm{Rb}^{+}(\mathrm{C} 222) \mathrm{Rb}-$ provided a real surprise! Instead of separated anions, the packing yielded pairs of anions, each trapped in a large dumbbell-shaped cavity about $12 \times 6 \times 4 \AA$ in size. Two views of the packing in the latter are shown in Figure 3. The cryptand molecules that encapsulate the cations are packed in such a way that the strands of one nest into the crevices of neighboring molecules. A nearly hexagonal arrangement of $\mathrm{Rb}^{+}(\mathrm{C} 222)$ or $\mathrm{K}^{+}(\mathrm{C} 222)$ results, that leaves $4 \AA$ diameter channels between the anionic cavities. Alternate layers are displaced by $1 / 2$ unit so that the channels and cavities form zig-zag chains through the structure. The interionic distance in an anion pair is shorter by at least 1.0. $\AA$ than that anticipated on the basis of the sizes of $\mathrm{K}^{-}$and $\mathrm{Rb}^{-} .[38]$ The anion dimers are, in turn well-separated from other pairs. By contrast, the $\mathrm{Na}^{-}$ions in both $\mathrm{Na}^{+}(\mathrm{C} 222) \mathrm{Na}^{-}$and in $\mathrm{K}^{+}(\mathrm{C} 222) \mathrm{Na}^{-}$ exist as separate anions rather than as dimers.[31,32]

The short $\mathrm{M}^{-}$to $\mathrm{M}^{-}$distances could result from packing effects. The highly polarizable anions would be easily compressed if the cavity size were too small to accommodate an undistorted pair of anions. On the other hand, the distances to hydrogens that line the cavity are normal. It is as if the molecules $K_{2}=$ and $R_{b_{2}}=$ were formed with bond lengths of $4.90 \AA$ and $5.13 \AA$ respectively. To first order, we would anticipate two bonding and two antibonding electrons from the $\sigma_{\mathrm{s}}$ and $\sigma_{s}{ }^{*}$ orbitals, respectively. Coulomb repulsion would be expected to lead to an unstable molecule.

To check for bonding contributions, Tientega et al carried out extensive $a b$ initio calculations on $\mathrm{K}_{2}, \mathrm{~K}_{2}^{-}$and $\mathrm{K}_{2}=$ in the gas phase.[54] Although Coulomb 


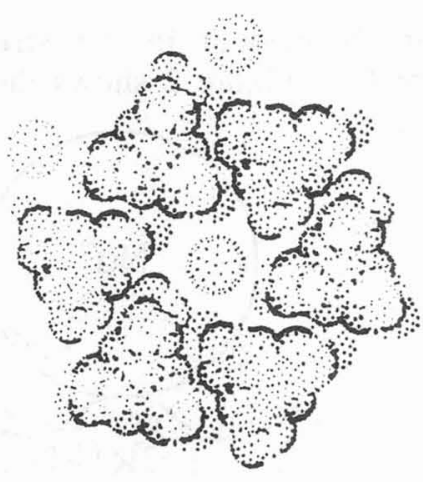

(a)

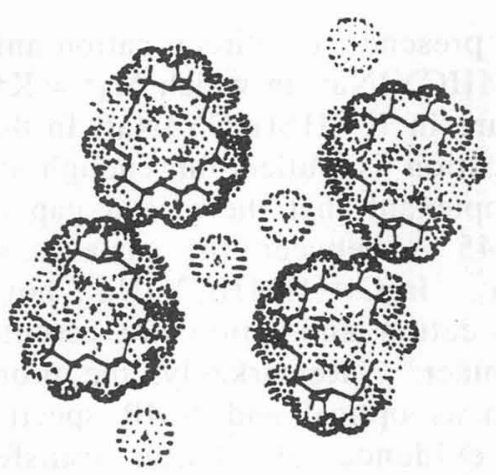

(b)

Figure 3. - Two views of the packing in $\mathrm{Rb}^{+}(\mathrm{C} 222) \mathrm{Rb}^{-}$. The circles represent the positions of the $\mathrm{Rb}^{-}$ions but are not to scale.

repulsion caused $\mathrm{K}_{2}=$ to be unstable with respect to both $2 \mathrm{~K}^{-}$and $\mathrm{K}_{2}^{-}+\mathrm{e}^{-}$, there was a substantial bonding contribution in $\mathrm{K}_{2}=$ with a minimum energy some $42 \mathrm{~kJ}$ below the Coulomb maximum. The optimum wave function mixes $\mathrm{n} s$ and $\mathrm{n} p$ contributions to lead to an $s p$-type hybridization. This accommodates a bonding pair of electrons between the nuclei while the remaining electron density "piles up" at each end. The singlet and triplet states of $\mathrm{K}_{2}=$ have calculated energy separations of $25 \mathrm{~kJ} \mathrm{~mol}^{-1}$.

Although gaseous $\mathrm{K}_{2}=$ is unstable, it could well be stabilized in the Coulomb field provided by an ionic crystal. To test this idea, calculations were made of the energies of $\mathrm{K}_{2}, \mathrm{~K}_{2}-$ and $\mathrm{K}_{2}=$ in the field of two protons placed at various distances on opposite ends of the molecular axis. At the equilibrium internuclear distance (4.5 $\AA$ ) of $K_{2}=$ when the protons are closer than $25 \AA$, the dianion becomes stable with respect to $\mathrm{K}_{2}^{-}+\mathrm{e}^{-}$. Thus, it appears that $\mathrm{K}_{2}=$ in $\mathrm{K}^{+}(\mathrm{C} 222) \mathrm{K}^{-}$is a stable species. We anticipate similar results for $\mathrm{Rb}_{2}=$. Similar calculations for $\mathrm{Na}_{2}=$ indicate that it, too, should be stable. However, the cavity formed by close-packing of $\mathrm{M}+(\mathrm{C} 222)$ in the configuration found for the potasside and rubidide is too large for the smaller anion dimer, $\mathrm{Na}_{2}=$. As a result, the cation packing is different and yields separated trapping sites for $\mathrm{Na}^{-}$.

The dianion site in $\mathrm{K}^{+} \mathrm{C} 222 \mathrm{~K}^{-}$is apparently too large for $\mathrm{Na}_{2}=$, and too small for $\mathrm{Cs}_{2}=$. The ceside, $\mathrm{Cs}^{+}(\mathrm{C} 222) \mathrm{Cs}^{-}$, has a very different structure from the potasside. As shown in Figure 4, the complexed cations no longer pack in in a pseudo-hexagonal fashion, Rather, three $\mathrm{Cs}^{+}$-cryptand units interlock as in $\mathrm{K}^{+}(\mathrm{C} 222) \mathrm{K}^{-}$, while the three that would complete the "hexagon" are displaced vertically by $1 / 2$ unit. This leads to a structure in which each $\mathrm{Cs}^{-}$has $n$ ine $\mathrm{Cs}^{+}(\mathrm{C} 222)$ units as nearest neighbors. The ceside anions form zig-zag chains through the structure with uniform $\mathrm{Cs}^{-}$to $\mathrm{Cs}^{-}$distances of only $6.38 \AA$ A.[35] Since the effective diameter of $\mathrm{Cs}^{-}$is $7.0 \AA$, the inter-ceside distances are shortened by about $0.6 \AA$.

The electronic structure that leads to dimer formation in $\mathrm{K}^{+}(\mathrm{C} 222) \mathrm{K}^{-}$and $\mathrm{Rb}^{+}(\mathrm{C} 222) \mathrm{Rb}^{-}$is also suitable for chain formation. The $s p$-like hybrid orbitals, with one electron available for each from the ceside anion, could easily form a 
chain of atoms with $\sigma$-type bonds. The zig-zag nature of the chain would be imposed by packing constraints.

Finally, the rubidide $\mathrm{Rb}^{+}(18 \mathrm{C} 6) \mathrm{Rb}^{-}$combines both structural features, chain formation and ion-pairing, to yield zig-zag chains of $\mathrm{Rb}^{-}$anions with short $(5.13 \AA)$ inter-anion distances.[38] Each $\mathbf{R b}^{-}$ion is in contact with an $\mathbf{R b}^{+}$cation that is coordinated to the six oxygen atoms of 18 -crown-6 but is displaced from the plane of the oxygens by $0.93 \AA$. These features are shown schematically in Figure 5.

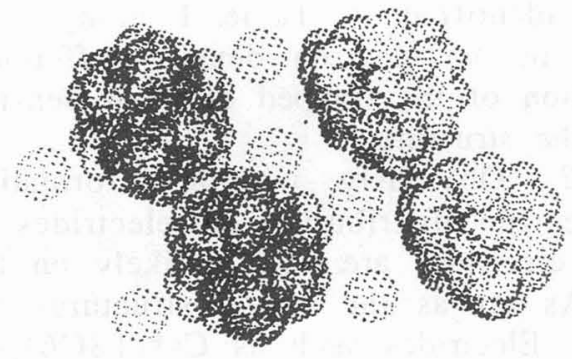

Figure 4. - Ion packing in the ceside, $\mathrm{Cs}^{+}(\mathrm{C} 222) \mathrm{Cs}^{-}$. The circles represent $\mathrm{Cs}^{-}$- locations but are not to scale.

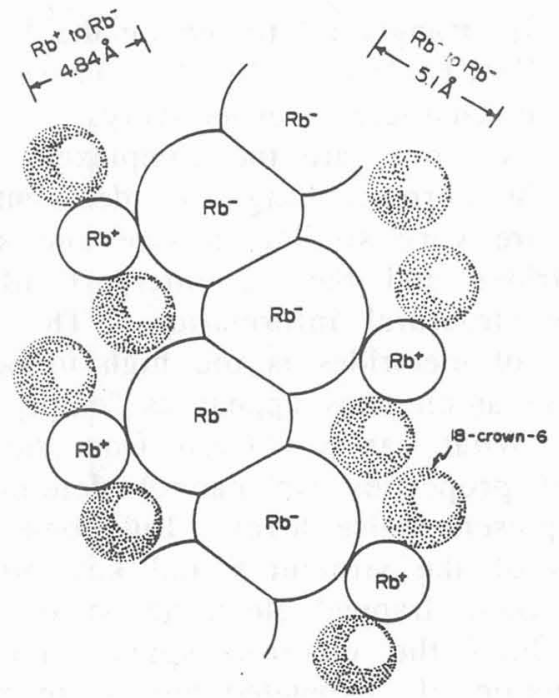

Figure 5. - Cation and anion packing in $\mathrm{Rb}^{+}(18 \mathrm{C} 6) \mathrm{Rb}^{-}$showing the chains of $\mathrm{Rb}^{-}$ and the contact ion-pairs between $\mathrm{Rb}^{+}$ and $\mathbf{R b}^{-}$.

\section{2 - Structures and Properties of Four Electrides}

Before the first determination of an electride crystal structure, we classified electrides as "localized" and "delocalized" based on the presumed behavior of the electrons as deduced from optical spectra, magnetic susceptibilities, powder and microwave conductivities and EPR spectra. In the former class, the electrons are trapped at energies well below the conduction band and behave rather independently of one another. We considered such electrides to be "stoichiometric F-centers". with electrons trapped at all anionic sites. By contrast, several electrides, notably $\mathrm{K}^{+}(\mathrm{C} 222) \mathrm{e}^{-}$and $\mathrm{Li}^{+}(\mathrm{C} 211) \mathrm{e}^{-}$, had optical spectra that were similar to those of metallic metal-ammonia solutions. These compounds also had high microwave conductivities, and their magnetic behavior showed substantial inter-electron interactions. While there was no direct evidence of metallic behavior, "delocalized" electrides were certainly more "metal-like" than were "localized" electrides.

\subsection{1 - Electride-Alkalide Structural Similarities}

The most striking feature of electride structures is their similarity to alkalides. Both show closest-packed complexed cations (except some cesides) 
with the details of the packing depending on the geometry of the complexant. The cation complexation geometries in electrides and in their corresponding alkalides are virtually identical, with the same cation to oxygen distances in both types of salts. Indeed, both have complexed cation structures that are very similar to those of normal salts.[27,28] This leads us to the conclusion that the "extra" electron density in electrides does not penetrate significantly into the interior region of the complexant. That is, the cationic charge on $\mathrm{M}^{+}$is not significantly reduced by the presence of trapped or itinerant electrons in the structure. This view is strongly reinforced by the ${ }^{133} \mathrm{Cs}$ NMR Knight shifts of $\mathrm{Cs}^{+}$in $\mathrm{Cs}^{+}(18 \mathrm{C6})_{2} \mathrm{e}^{-}$ and $\mathrm{Cs}^{+}(1.5 \mathrm{C} 5)_{2} \mathrm{e}^{-} \cdot[29,48]$ These correspond to only 0.033 and 0.063 percent atomic character, respectively.

Not only are the complexed cation structures virtually identical in electrides and the corresponding alkalides, but also each electride has "X-ray empty" holes that are very similar in size and shape to the anion sites in an alkalide. The electrides and their counterpart alkalides are identified in Table 1 along with some structural information. The noise level in the electron density difference maps of electrides is too high to permit detection of the trapped electron density, so the anion sites appear as "empty" holes in the structure.

What can we learn from the structures? Obviously, without information about properties we cannot determine the electron distribution in electrides at the present noise level. But some models of electrides are very unlikely on the basis of the structures and key properties. As far as the cation structures are concerned, trapped electrons behave as anions. Electrides such as $\mathrm{Cs}^{+}\left(18 \mathrm{C}^{6}\right)_{2} \mathrm{e}^{-}$, in which the electron spins interact only weakly, cannot be described as a collection of "expanded atoms" in which the electrons occupy Rydberg-like states at the periphery of the complexant. If this were the case, the close-packing of the cations would result in overlap of the electron wave functions and the formation of a band structure as in a metal. Clearly, electron localization occurs, and the logical center of such localization is the anionic site.

\subsection{2 - Localized Electrides}

$\mathrm{Cs}^{+}(18 \mathrm{C6})_{2} e^{-:}$: The prototypical localized electride is $\mathrm{Cs}^{+}(18 \mathrm{C6})_{2} \mathrm{e}^{-}$. It crystallizes in the monoclinic space group $\mathrm{C} 2 / \mathrm{c}$ with four molecules per unit cell.[27] Figure 6 shows a schematic diagram of the locations of the complexed $\mathrm{Cs}+(18 \mathrm{C} 6)_{2}$ cations relative to the anionic site as well as the location of the six anionic sites nearest to a given one. We assumed in labelling this diagram that the center of charge of the trapped electron is at the center of the anionic site. Using van der Waals radii to define the boundaries of the cavity, we find that it has roughly the shape of an American football with a long axis along $c$ of about 7 $\AA$ and a diameter of about $4 \AA$. The interelectron distance along $c$ is $8.68 \AA$, while electrons along axes at $\sim 45^{\circ}$ to $a$ and $b$ are located $10.27 \AA$ from the central trapping site. A relatively short open channel, about $1 \times 2 \AA$ in size at its narrowest point, connects trapping sites along the $c$ axis while the other channels are longer and more constricted.

The existence of one trap per electron and the relatively large interelectron distances make the properties of this electride understandable. The magnetic susceptibility follows the Curie-Weiss law with a small Weiss constant $(-1.5 \mathrm{~K})[55,56]$, the optical spectrum consists of a single broad peak in the near 
IR at $1650 \mathrm{~nm}[45,56]$, and the Knight shift of the ${ }^{133} \mathrm{Cs}$ signal is small, corresponding to only 0.033 percent atomic character at $\mathrm{Cs}^{+} \cdot[27,48]$ The latter is to be compared with a value of $0.2 \%$ in dilute $\left(10^{-2}\right.$ to 1 MPM) cesium-ammonia solutions. Early EPR spectra of $\mathrm{Cs}^{+}(18 \mathrm{C} 6)_{2} \mathrm{e}^{-}$showed only a single exchangenarrowed line at the free electron g-value [55] and initial powder conductivities indicated semiconducting behavior with an apparent band gap of $0.9 \mathrm{eV} .[56]$ Mixed sodide-electride samples can be made that correspond to substitution of $\mathrm{Na}^{-}$for $\mathrm{e}^{-}$, up to a mole fraction of about 0.12 in sodium.[48] The ${ }^{133} \mathrm{Cs} \mathrm{NMR}$ spectra show that up to three electrons around some complexed $\mathrm{Cs}^{+}$cations can be replaced by $\mathrm{Na}^{-}$. This is apparently permitted by the isostructural nature of $\mathrm{Cs}^{+}(18 \mathrm{C} 6)_{2} \mathrm{e}^{-}$and $\mathrm{Cs}^{+}(18 \mathrm{C} 6)_{2} \mathrm{Na}^{-}$and the nearly equal cavity sizes and shapes.
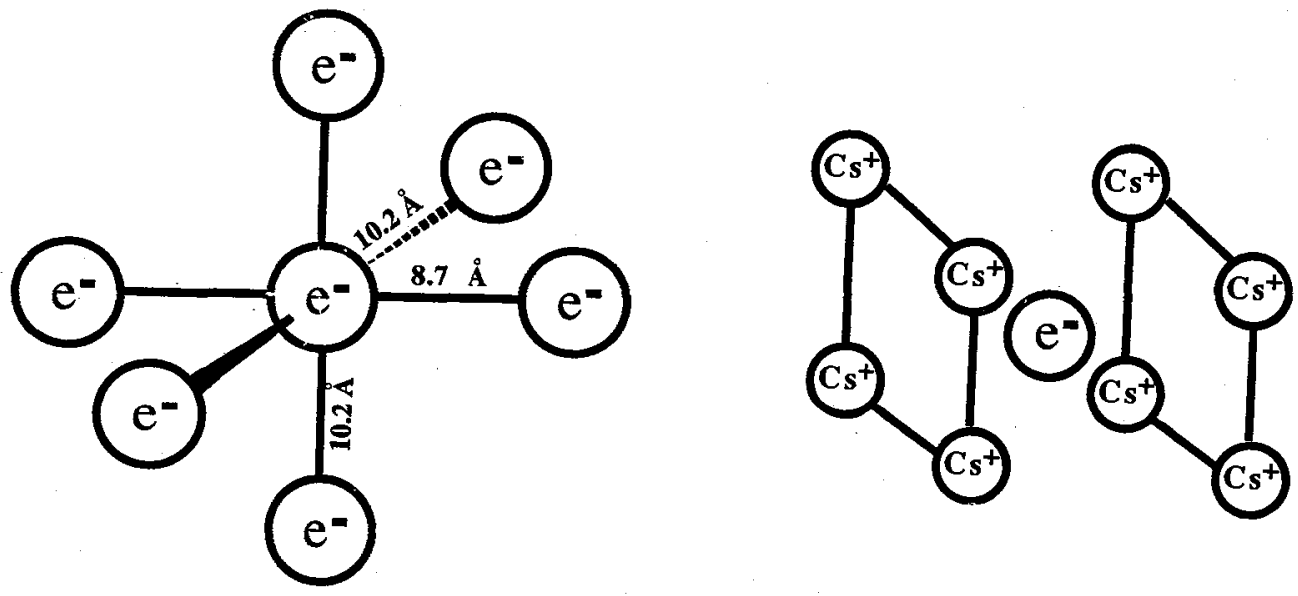

Figure 6. - Presumed locations of the centers of charge of trapped electrons and interionic distances in $\mathrm{Cs}^{+}(18 \mathrm{C} 6)_{2} \mathrm{e}^{-}$.

The story of $\mathrm{Cs}^{+}(18 \mathrm{C} 6)_{2} \mathrm{e}^{-}$would have been closed except for recent studies that showed a marked dependence of the powder conductivities [57] and EPR spectra [58] on "doping" by ceside, $\mathrm{Cs}^{-}$. Samples that were prepared in the presence of excess $18 \mathrm{C} 6$ to minimize $\mathrm{Cs}^{-}$formation were several orders of magnitude less conducting than the original samples. Although the latter showed no $\mathrm{Cs}^{-}$NMR peak and had nominally the electride stoichiometry, they could easily have contained as much as $1 \%$ excess cesium. "Pure" $\mathrm{Cs}^{+}(18 \mathrm{C} 6)_{2}$ samples showed very low electronic conductivities, and, in fact, above $200 \mathrm{~K}$ the conductivity was dominated by cationic current carriers. The same samples showed a well-defined axial EPR pattern without exchange narrowing.[58] Evidently, the presence of $\mathrm{Cs}^{-}$, which is too large to fit into the electride cavities, has a profound effect on the transport properties. The presence of comparable amounts of the smaller $\mathrm{Na}^{-}$ion had no effect on the conductivity.[57]

We propose that $\mathrm{Cs}^{-}$cannot fit into the cavity and, as a result, partial ionization occurs to yield trapped $\mathrm{Cs}$ atoms and an electron in an expanded orbital about the doping center. This electron could provide activated conductivity by 
thermal promotion to the conduction band. Migration of $\mathrm{Cs}^{+}$from one Cs center to an adjacent trapped electron site could not only provide an electron exchange mechanism but could also form the basis for cationic conductivity. The latter would be initiated by dissociation of $\mathrm{Cs}^{+}(18 \mathrm{C} 6)_{2}$ to yield Cs trapped at the anionic site. Transfer of $\mathrm{Cs}^{+}$to an adjacent site would provide a mechanism for cationic conductivity.

The new conductivity results require that the electron in pure $\mathrm{Cs}^{+}(18 \mathrm{C} 6)_{2} \mathrm{e}^{-}$ be trapped at least $1 \mathrm{eV}$ below the conduction band. This means that the optical spectrum does not arise solely from bound-continuum transitions. There must be bound states between the conduction band and the ground state. In other words, the localized electron in $\mathrm{Cs}^{+}(18 \mathrm{C} 6)_{2} \mathrm{e}^{-}$is even more tightly bound than previously thought.

$\mathrm{Cs}^{+}(15 \mathrm{C5})_{2} \mathrm{e}^{-}$: This electride has many features in common with $\mathrm{Cs}(18 \mathrm{C} 6)_{2} \mathrm{e}^{-}$ but there are major differences as well. The crystal structure belongs to the triclinic space group Pï with one molecule per unit cell.[28] It is isostructural with $\mathrm{Cs}^{+}(15 \mathrm{C} 5)_{2} \mathrm{Na}^{-}$but has nearly spherical "empty" cavities of mean diameter $4.7 \AA$ at the $\mathrm{Na}^{-}$sites. Each anionic site in the electride is surrounded by eight nearest-neighbor complexed cesium cations, two each at distances of $6.92,7.63$, 8.23 and $8.38 \AA$. The electron trapping sites are connected by very constricted channels in two directions and a more open channel in a third direction. The distances between the centers of the anionic sites are $8.60,8.89$ and $9.94 \AA$ (two at each distance). Thus, as with $\mathrm{Cs}^{+}(18 \mathrm{C} 6)_{2} \mathrm{e}^{-}$, there exist one-electron trapping sites in $\mathrm{Cs}^{+}(15 \mathrm{C} 5)_{2} \mathrm{e}^{-}$that are relatively well-separated from one another.

The properties of $\mathrm{Cs}^{+}(15 \mathrm{C} 5)_{2} \mathrm{e}^{-}$confirm the localized nature of this electride.[29] As with $\mathrm{Cs}^{+}(18 \mathrm{C} 6)_{2} \mathrm{e}^{-}$, there is a pronounced effect on the conductivity as a result of $\mathrm{Cs}^{-}$doping.[57] Even with "undoped" samples, however, the X-band EPR spectrum shows the effects of exchange narrowing. The major difference between $\mathrm{Cs}^{+}(15 \mathrm{C} 5)_{2} \mathrm{e}^{-}$and other localized electrides is the presence of an antiferromagnetic transition at $4.6 \mathrm{~K}$ in carefully annealed polycrystalline samples. The fact that a "spin-flop" occurs at $2 \mathrm{~K}$ with field strengths of $0.5 \mathrm{~T}$ shows that the magnetic anisotropy is weak.[29]

Solid-state ${ }^{133} \mathrm{Cs}$ NMR studies show that the electron density at $\mathrm{Cs}^{+}$is higher than that in $\mathrm{Cs}^{+}(18 \mathrm{C} 6)_{2} \mathrm{e}^{-}$, but it still has only 0.063 percent atomic character. NMR studies, differential scanning calorimetry and magnetic susceptibilities all show that an endothermic phase transition occurs at $266 \mathrm{~K}$ to give a less paramagnetic state.[29] This appears to be partial melting with considerable motion of the crown ether. Complete melting to give an unstable blue liquid occurs at $\sim 295 \mathrm{~K}$.

The optical absorption spectrum of thin films of $\mathrm{Cs}^{+}(15 \mathrm{C} 5)_{2} \mathrm{e}^{-}$produced by rapid solvent evaporation is unusual. Three peaks occur at 900-950, 1250 and 1600-1700 $\mathrm{nm}$ rather than the single broad peak usually observed with localized electrides.[29] - The origin of the three peaks is not known, although it has been suggested that they might arise from non-degenerate transitions from the $s$-like ground state to three excited $p$-states. Because of the polycrystalline nature of the films and the unknown way in which crystallization occurs upon solvent evaporation, any explanation of the unusual optical spectrum of $\mathrm{Cs}^{+}(15 \mathrm{C5})_{2} \mathrm{e}^{-}$is tentative. 
Other localized electrides: A number of other polycrystalline electrides of unknown structure appear, on the basis of their optical spectra and magnetic susceptibilities, to be localized. Included are $\mathrm{Rb}^{+}(15 \mathrm{C} 5)_{2} \mathrm{e}^{-}$and $\mathrm{K}^{+}(15 \mathrm{C5})_{2} \mathrm{e}^{-}$. Numerous attempts to prepare and characterize solvent-free non-sandwich electrides such as $\mathrm{K}^{+}(18 \mathrm{C} 6) \mathrm{e}^{-}$and $\mathrm{Rb}^{+}(18 \mathrm{C} 6) \mathrm{e}^{-}$have failed. All preparations made to date appear to be alkalide-electride mixtures and/or to contain solvent in the crystals.

\subsection{3 - Electrides with Substantial $e^{-}$to $e^{-}$Interactions}

$K+(C 222) e^{-:} \quad$ This electride shows the most unambiguous structural and behavioral evidence for relatively strong inter-electron interactions and for electron delocalization. [36] Its crystal structure is similar to (but not isostructural with) those of $\mathrm{K}^{+}(\mathrm{C} 222) \mathrm{K}^{-}$and $\mathrm{Rb}^{+}(\mathrm{C} 222) \mathrm{Rb}^{-} . \mathrm{K}^{+}(\mathrm{C} 222) \mathrm{e}^{-}$crystallizes in the monoclinic space group $\mathrm{C} 2 / \mathrm{c}$ with eight molecules per unit cell.[37] The dumbbell-shaped cavities of approximate dimensions $4 \times 6 \times 12 \AA$ are connected with very open $(\sim 4 \AA$ diameter) channels in one direction and more constricted channels in another direction. The cavities are nearly identical in shape to those which trap pairs of $\mathrm{K}^{-}$or $\mathrm{Rb}^{-}$ions as the dimers, $\mathrm{M}_{2}=$. Each cavity is clearly large enough to trap two electrons. If the electrons are located at the anionic sites, the separation of the centers of charge in the pair is $\sim 5.3 \AA$ while the next nearest trapping site is $\sim 7.8 \AA$ away through the large open channel. Through the other channel an electron trapping site exists at a distance of $\sim 8.4 \AA$. A view of the trapping sites and channels is shown in Figure 7 . Thus, in contrast to the structures of the localized electrides, that of $\mathrm{K}+(\mathrm{C} 222) \mathrm{e}^{-}$strongly suggests that the electron trapping sites are pair-wise close together, which would lead to much stronger electron-electron interactions.

Early evidence for electron delocalization and possible metallic character came from the optical absorption spectrum of films of $\mathrm{K}^{+}(\mathrm{C} 222) \mathrm{e}^{-}$produced by evaporation of ammonia from a solution of this stoichiometry.[43] Although earlier films from methylamine [42] showed a localized-type spectrum, with a distinct peak in the near IR, films from ammonia had a spectrum that was nearly identical to those of metallic metal-ammonia solutions (at $\sim 12$ MPM). Recent films of $\mathrm{K}^{+}(\mathrm{C} 222) \mathrm{e}^{-}$prepared without solvent in a belljar by vapor deposition $[59,60]$ have spectra which are best described as a combination of a trapped electron peak and a plasmon absorption.[61] Recall that such spectra were also observed by reflectance in metal-ammonia solutions near the onset of the nonmetal to metal transition.[26] Figure 8 shows the three types of absorption spectra of $\mathrm{K}^{+}(\mathrm{C} 222) \mathrm{e}^{-}$films. Evidently, the optical absorption spectrum in this case is very sensitive to the method of formation of the film.

Evidence for electron spin-pairing in $\mathrm{K}^{+}(\mathrm{C} 222) \mathrm{e}$-comes from static magnetic susceptibility studies.[36] The susceptibility (corrected for a small low temperature "Curie tail") becomes slightly diamagnetic as $\mathrm{T} \rightarrow 0$. The susceptibility increases gradually with increasing temperature, corresponding to $\sim 14 \%$ unpaired spins at $200 \mathrm{~K}$. Studies could not be carried out at much higher temperatures because of instability of the electride and the tendency of the SQUID temperature to overshoot. The simplest explanation of the magnetic behavior is that the 


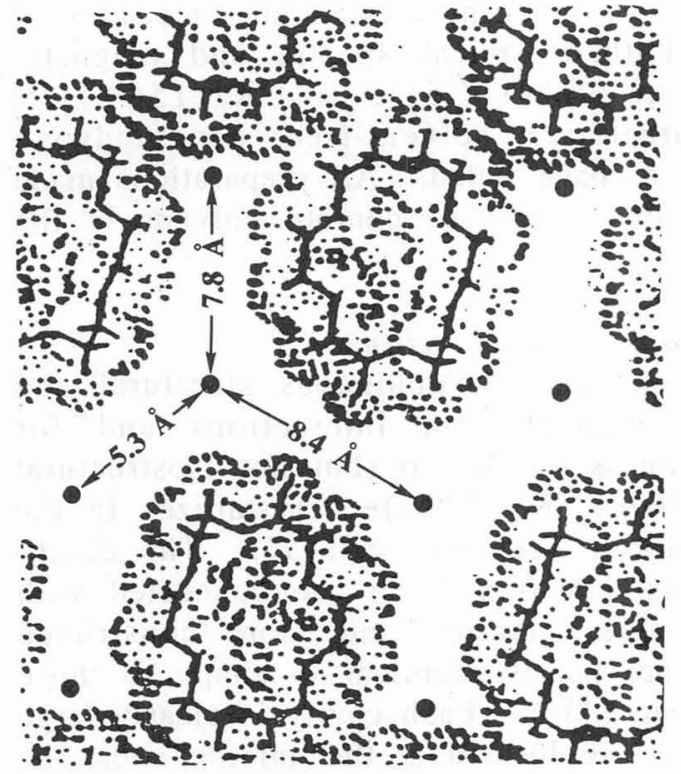

Figure 7. - View of the electronpair trapping sites and channels in $\mathrm{K}^{+}(\mathrm{C} 222) \mathrm{e}^{-}$

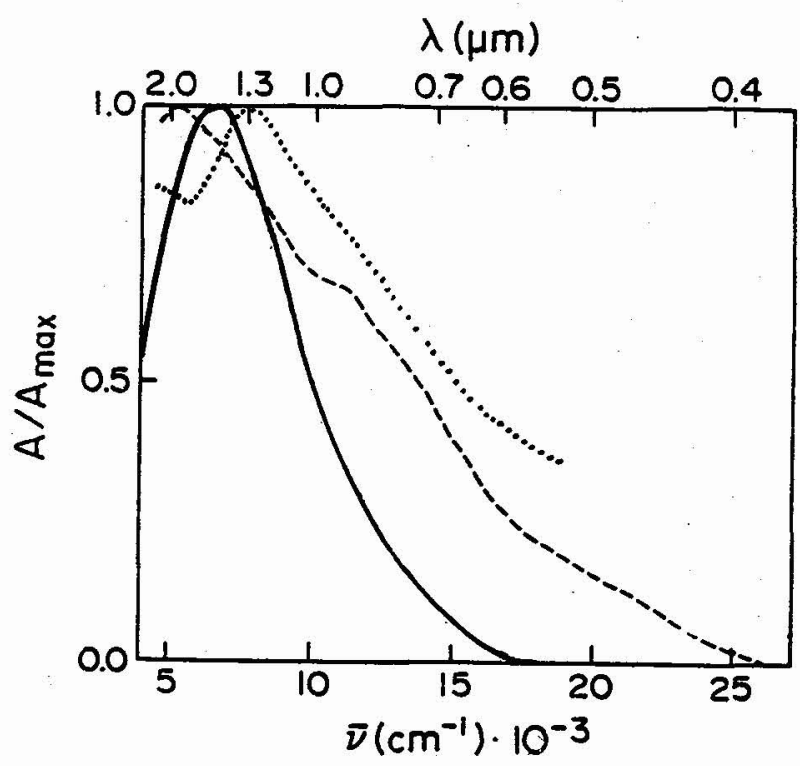

Figure 8. - Optical spectra of films of $\mathrm{K}+(\mathrm{C} 222) \mathrm{e}^{-}$prepared by various methods: Solid line, by evaporation of methylamine [42]; Dashed line, by evaporation of ammonia [43]; Dotted line, by vapor deposition under high vacuum without solvent.[61]

ground state consists of singlet electron pairs, but that a thermally accessible triplet state lies about $0.05 \mathrm{eV}$ above the ground state.

The microwave conductivity of $\mathrm{K}^{+}(\mathrm{C} 222) \mathrm{e}^{-}$is so high that it is difficult to measure the EPR spectrum because of severe degradation of the cavity " $Q$ ". Preliminary measurements on very small samples suggest that the observed signal arises from defect electrons. rather than from the triplet state, since the EPR intensity follows the Curie law, whereas the susceptibility shows that the sample becomes much more paramagnetic as the temperature is increased.[36]

Both dc and ac conductivities of packed powders and pellets confirm the high conductivity of $\mathrm{K}^{+}(\mathrm{C} 222) \mathrm{e}^{-}$.[57] There is evidence that electrode effects and grain boundary resistance still dominate the measurements and may be responsible for the observed activation energy of $\sim 0.07 \mathrm{eV}$. Thus, the observed resistivity of $0.2 \mathrm{ohm} \mathrm{cm}$ at $130 \mathrm{~K}$ represents an upper limit. It will require fourprobe single crystal conductivity measurements to determine the true 
conductivity and the presence or absence of an activation barrier. So far, all attempts at such measurements have failed because of sample-handling problems.

$\mathrm{Li}^{+}(\mathrm{C} 211) \mathrm{e}^{-:}$It has been 10 years since Steve Landers and $\mathrm{I}$, in collaboration with Mike Sienko and Angelica Stacy, studied the optical and magnetic behavior of powders and films of $\mathrm{Li}^{+}(\mathrm{C} 211) \mathrm{e}^{-}$produced by solvent evaporation.[63] After much effort, we have finally been able to crystallize this compound and determine its structure and properties.[64] The work is still in progress, but we can report at this time the confirmation of a susceptibility maximum at $\sim 20 \mathrm{~K}$ and an optical spectrum that seems to have a combination of localized and plasmon behavior. The structure shows the presence of zig-zag chains of cavities with rather open channels in two directions and inter-cavity separations of $7.91,8.15$ and $8.38 \AA$. The fact that the low temperature susceptibility drops well below $2 / 3$ of its maximum value rules out a conventional 3D antiferromagnetic transition. Measurements of NMR and EPR spectra and of conductivities are in progress.

\section{3 - Electrons Trapped in Alkalides}

Because of the solution equilibrium described by Eqn. 2,

$$
\mathrm{M}_{\text {solv }} \rightleftarrows \mathrm{M}^{+} \text {solv }+2 \mathrm{e}^{-} \text {solv }
$$

it is virtually impossible to synthesize an alkalide that does not contain some trapped electrons and vice-versa. So far, only $\mathrm{Na}^{+}(\mathrm{C} 222) \mathrm{Na}^{-}$can be made virtually free of trapped electrons, $\mathrm{e}^{-} \mathrm{t}$, as determined by EPR spectroscopy. By using an excess. of metal and a solvent such as $\mathrm{Me}_{2} \mathrm{O}$ in which the metals are insoluble, the concentration of trapped electrons can be kept small, but they are always easily detectable by EPR. One can take advantage of this electron doping to study the nature of electrons trapped in alkalides. To the extent that they are trapped at the same types of sites as in electrides, these studies also give us information about the local environment of the electron in electrides. But the concentration is low enough to avoid complications that arise from electron exchange and electron-electron interactions.[58]

The information that can be gained from EPR studies of electrons trapped in alkalides includes spin concentration as a function of temperature, lineshapes, and saturation behavior to assess the distribution of trapping sites, hyperfine coupling to nearby nuclei, and deviations from isotropic symmetry as deduced from the principal values of the g-tensor. By using electron-nuclear double resonance (ENDOR), pulsed EPR, including electron spin echo envelope modulation spectroscopy (ESEEM), and various pulse sequences, it is possible to create a rather precise map of the electron densities at various nuclei. A complete discussion of these effects is beyond the scope of this article, and many of the techniques are in the initial stages of application to alkalides and electrides.

The results to date are clearly in accord with an "F-center model" in which the electron is trapped at a vacant anion site. The electron density is not confined to the "empty hole" described by the van der Waals surfaces of 
surrounding molecules. Rather, there is some contact density at the hydrogens of neighboring complexant molecules and even at alkali metal cations and anions as far away as 8-10 $\AA$. But, in all cases except those in which a contact ion-pair exists between $\mathrm{M}^{+}$and $\mathrm{M}^{-}$, such as in $\mathrm{M}^{+}(\mathrm{HMHCY}) \mathrm{Na}^{-}$[57], the contact densities at the alkali metal nuclei are well below $1 \%$ of the free atom value. As with NMR Knight shifts, the EPR spectra show that trapped electrons have very low contact densities at alkali cations that are encapsulated in a cryptand or a crown ether sandwich.[58] When, however, the cation is not well-shielded by the complexant, so that it can make an ion-pair with $\mathrm{M}^{-}$, the contact densities of trapped electrons at $\mathrm{M}^{+}$can be as large as $15 \%$ of the free atom value. Once again, these results are in accord with electron trapping at vacant anion sites.

We conclude on the basis of structures and properties that electrons in alkalides and in electrides are trapped at anionic sites as is true for F-centers in alkali halides. But the wave function must extend beyond the cavity, probably assisted by the positive charges on the $-\mathrm{C}-\mathrm{H}$ bonds as a result of the electronwithdrawing power of the ether oxygens. In localized electrides, however, the "tail" of the electron density distribution must not be large beyond about $4 \AA$, since electron-electron interactions are weak.

\section{4. - Metal Solutions Revisited}

Alkalides and electrides owe their parentage to metal solutions in ammonia, amines, ethers and other solvents. It is only fitting, then, that alkalides and electrides can also contribute to our knowledge of metal solutions and provide new liquid systems for study. It seems clear that systems of this kind can break the dependence of metal solution chemists on ammonia as a solvent. Indeed, Edwards and co-workers have already provided much information about species in metal solutions by using crown ethers, either neat or in solution, to provide high concentrations of $\mathrm{e}^{-}$solv and/or $\mathrm{M}^{-}$solv.[66-68]

By using the affinity of lithium for primary amines, we have begun to examine concentrated solutions that do not contain macrocyclic or macrobicyclic complexants. Also, the extraordinary affinity of alkali metal cations for the appropriate crown ether or cryptand permits us to make very concentrated alkali metal solutions in solvents that cannot dissolve appreciable amounts of alkali metals by themselves. We argue that both of these types of solutions provide new opportunities to study the nature of metal solutions and such phenomena as the non-metal to metal transition.

\section{1 - Amine Complexants for $\mathrm{Li}^{+}$}

\subsection{1.- $\mathrm{Li}\left(\mathrm{MeNH}_{2}\right)_{4}$}

The compound $\mathrm{Li}\left(\mathrm{MeNH}_{2}\right)_{4}$ is intriguing, and in the solid state may represent the first localized electride to be studied. Sienko and others studied this compound years ago and found that, while the liquid appears to be metallic, the solid has the magnetic characteristics of a semiconductor.[22] More data, especially structures and conductivities are needed to establish the nature of $\mathrm{Li}\left(\mathrm{MeNH}_{2}\right)_{4}$. It is intriguing to speculate that electrons, which are delocalized in a conduction band in the liquid, may be locally trapped in the solid. 


\subsection{2 $-\mathrm{Li}^{+}(\mathrm{EDA})_{2} \mathrm{Na}^{-}$}

Although both lithium and sodium have limited solubilities in ethylenediamine (EDA), it is possible to form the stoichiometric compound $\mathrm{Li}^{+}(\mathrm{EDA})_{2} \mathrm{Na}^{-}$ .[69] This compound can be prepared by dissolving stoichiometric amounts of $\mathrm{Li}$ and $\mathrm{Na}$ in ammonia, evaporating the solvent and taking up the residue in methylamine to which two moles of EDA per mole of $\mathbf{L i}$ has been added. Evaporation of the methylamine and/or the addition of $\mathrm{Me}_{2} \mathrm{O}$ yields the solid compound.

$\mathrm{Li}^{+}(\mathrm{EDA})_{2} \mathrm{Na}^{-}$is a bright gold-colored liquid that freezes at $\sim-25$ oC to yield a gold-colored solid. Both ${ }^{7} \mathrm{Li}$ and ${ }^{23} \mathrm{Na} \mathrm{NMR}$ spectra of the liquid and the solid confirm the presence of $\mathrm{Li}^{+}$and $\mathrm{Na}^{-}$both above and below the freezing point. At about $0 \circ \mathrm{C}$, it appears that decomplexation occurs, with the sample becoming heterogeneous. The dark blue, viscous liquid that surrounds the suspended particles makes it difficult to examine the decomplexation process. The sample decomposes completely at about $35{ }^{\circ} \mathrm{C}$.

We have not yet been able to grow single crystals of $\mathrm{Li}^{+}\left(\mathrm{EDA}_{2}\right)_{2} \mathrm{Na}^{-}$. In view of the tendency of $\mathrm{Li}^{+}$and complexants to include solvent in the structure [41] and/or to deprotonate amines, the compound could well be more complex than implied by the simple formula we use. In any event, this system was the first to provide an authentic liquid sodide.

\subsection{3 - Lithium Sodides in $\mathrm{MeNH}_{2}$ and $\mathrm{EtNH}_{2}$}

The stability of $\mathrm{Li}^{+}\left(\mathrm{MeNH}_{2}\right)_{4}$ in lithium-methylamine solutions provided an explanation for the solubility of lithium-cesium solutions in 1-propylamine (1-PrNH2) when $18 \mathrm{C} 6$ was present. Such solutions are much more stable than similar solutions without lithium and provided the first crystals of $\mathrm{Cs}^{+}\left(18 \mathrm{C}^{6}\right)_{2} \mathrm{Cs}^{-}$ [thought at first to be the electride, $\mathrm{Cs}^{+}(18 \mathrm{C} 6) \mathrm{e}^{-} .[70]$ The synthesis involved prior formation of solutions in methylamine, removal of most of the $\mathrm{MeNH}_{2}$ and introduction of 1-propylamine $\left(1-\mathrm{PrNH}_{2}\right)$. If all of the $\mathrm{MeNH}_{2}$ were removed, the sample would not dissolve completely and was very unstable in $1-\mathrm{PrNH}_{2}$. The solubility of $\mathrm{Li}$ in $1-\mathrm{PrNH}_{2}$ was apparently provided by its stability as the complex ion $\mathrm{Li}^{+}\left(\mathrm{MeNH}_{2}\right) 4$.

The solubilization of lithium in various solvents as the methylamine complex proved to be rather general.[71] It also provided the opportunity to dissolve sodium in solvents in which sodium alone is either insoluble or only slightly soluble. The synergistic effect of lithium is probably caused by the formation of the sodide, $\mathrm{Li}^{+}\left(\mathrm{MeNH}_{2}\right)_{4} \mathrm{Na}^{-}$. Thus, while sodium is only slightly soluble in $\mathrm{MeNH}_{2}$, very concentrated solutions (at least up to ratios of $\mathrm{Li}: \mathrm{Na}: \mathrm{MeNH}_{2}$ of $\left.1: 1: 8\right)$ can be formed with equal amounts of lithium and sodium. Whether the pure sodide, $\mathrm{Li}^{+}\left(\mathrm{MeNH}_{2}\right){ }_{4} \mathrm{Na}^{-}$, can be formed or not is still an open question.

The study of amine complexants for $\mathrm{Li}^{+}$is still ongoing.[72] It appears that EtNH 2 can be used in place of $\mathrm{MeNH}_{2}$ and that other alkalide ions, $\mathrm{K}^{-}, \mathrm{Rb}^{-}$or $\mathrm{Cs}^{-}$ can be substituted for $\mathrm{Na}^{-} .[72]$ It now appears that $\mathrm{Li}^{+}(\mathrm{EtNH})_{4} \mathrm{Na}^{-}$is the lowestmelting fused salt known ( -75 $\left.{ }^{\circ} \mathrm{C}\right)$. 
The existence of alkalides with smaller cations than are present when crown ethers or cryptands are used raises the intriguing question, "Could an alkalide be metallic?". Alkali metal anions are isoelectronic with their neighboring alkaline earth atoms. If $\mathrm{M}^{-}$ions were brought close enough together for their wavefunctions to overlap strongly, the $p$-band and $s$-band might cross, leading to metallic behavior. A clue might be provided by the Herzfeld criterion for metallization, [73] which has been shown to be rather general.[25,74] According to this criterion, if $4 / 3 \pi \mathrm{N}_{\mathrm{av}} \alpha / \mathrm{V}_{\mathrm{m}}$ is greater than 1.0 , the system is metallic. In this expression $\alpha$ is the molecular polarizability and $V_{m}$ is the molar volume. While $\alpha$ is unknown for alkali metal anions in the condensed phase, gas phase values are clearly large enough to predict metallization at the separation distances in $\mathrm{Li}^{+}(\mathrm{EDA})_{2} \mathrm{M}^{-}$and similar compounds. These possibilities are being investigated in our lab and elsewhere.

\section{2 - Metal Solutions in Dimethyl Ether}

Dimethyl ether, $\mathrm{Me}_{2} \mathrm{O}$, in the presence of crown ether, aza-crown or cryptand complexants, is an intriguing solvent for alkali metals. It is a nonviscous liquid that boils at $-26{ }^{\circ} \mathrm{C}$. At and below this temperature, it has a dielectric constant that is about the same [7-8] as that of THF at room temperature. While not as good a solvent for ionic compounds as THF, many salts show reasonable solubilities. The solvent is easy to purify by forming a solution of $\mathrm{Na} / \mathrm{K}$ - benzophenone, and it can be conveniently stored in small stainless steel tanks.[75,76] To anyone familiar with handling liquid ammonia by vacuum-line techniques, $\mathrm{Me}_{2} \mathrm{O}$ is easy to handle.

The alkali metals are insoluble in $\mathrm{Me}_{2} \mathrm{O}$ in the absence of complexants but can be very soluble when crown ethers or other complexants are present. For example, the minimum solubility of $\mathrm{K}^{+}(15 \mathrm{C} 5)_{2} \mathrm{~K}-$ in $\mathrm{Me}_{2} \mathrm{O}$ at $-78{ }^{\circ} \mathrm{C}$ is $0.5 \mathrm{M}$ and it may be much higher than this. By changing the ratio of $15 \mathrm{C} 5$ to $\mathrm{K}$, one can obtain solutions of either the potasside or the electride. The full range of metals and complexants that could be used has not been explored, but clearly, it would be easy to study relatively concentrated solutions that contain $\mathrm{M}^{-}$solv and/or $\mathrm{e}^{-}$solv in $\mathrm{Me}_{2} \mathrm{O}$ with a complexed counter-ion $\left[\mathrm{M}^{+}(\right.$Complexant $\left.)\right]$. Furthermore, a different alkali metal could be used for the cation than for the anion. For example, one can make concentrated solutions of $\left.\mathrm{Cs}^{+}(18 \mathrm{C} 6)_{2} \mathrm{~K}^{-}\right)$in $\mathrm{Me}_{2} \mathrm{O}$.

A further distinct advantage of $\mathrm{Me}_{2} \mathrm{O}$ is its inertness to reduction. Having no acidic hydrogens and no hydrogens $\beta$ to oxygen, this solvent can provide very stable metal solutions. These qualities also make it suitable for aprotic reductions by $\mathrm{M}^{-}$solv or $\mathrm{e}^{-}$solv . It is possible to prepare small (<30 $\AA$ to $150 \AA$ ) metallic particles of transition metals, noble metals, and post-transition metals by titration of precursor metal compounds dissolved in $\mathrm{Me}_{2} \mathrm{O}$ with solutions of alkalides and electrides.[77]. Alkalides and electrides should be very useful for aprotic reductions of organic compounds and the synthesis of organometallic compounds. Inorganic, metal-organic and organic chemists interested in synthesis should pursue the use of alkalides and electrides in $\mathrm{Me}_{2} \mathrm{O}$ and/or THF for aprotic reductions. 


\section{5 - Summary and Future Directions}

As described in this paper, solid alkalides and electrides have many species in common with metal solutions. Indeed, the complexant, by providing a substitute for the primary solvation layer of the cation, makes it possible to produce a crystalline analog of concentrated alkali metal solutions in ammonia, amines and ethers. The wide variety of structures observed for crystalline alkalides and electrides provides examples of isolated metal anions and trapped electrons, cation-anion contact ion-pairs, anion and electron dimers, and anionic chains. Such variety is made possible by the many choices that are available among complexants and by the ability to select complexants that are appropriate for each of the alkali cations.

It is anticipated that new assemblies will result with still other systems. For example, could we double the electron/anion density by complexing an alkaline earth cation? So far such combinations have been very unstable to irreversible decomposition, but there should be a cation-complexant combination that is more stable. By using aromatic groups on the complexant, new compounds that contain aromatic radical anions or aromatic dianions that encapsulate an alkali or alkaline earth cation should be possible. Again, our preliminary work along these lines has not yielded stable compounds. Other combinations, such as encapsulation of two cations within a single cage molecule, or the trapping of a stable dimer cation such as $\mathrm{Li}_{2}{ }^{+}$, may be possible. The field of alkalide-electride synthesis is a rich one that should attract other investigators because of the wide variety of solid-state properties that might be achieved.

In addition to their appeal in materials research, alkalides and electrides could open new avenues for the study and utilization of alkali metal solutions. By providing relatively stable, concentrated solutions in such aprotic solvents as $\mathrm{Me}_{2} \mathrm{O}$ and THF as well as very concentrated solutions in a number of amines, alkalides and electrides open the possibility of extending metal-ammonia studies to other solvents without the frustrations caused by low solubilities. For the synthetic chemist, the availability of the strongest reducing agents known, as relatively stable solutions in aprotic solvents, should provide new methods for the synthesis of low oxidation state inorganic compounds and difficult-to-prepare organometallic compounds.

\section{Acknowledgments}

This research was supported in part by U. S. National Science Foundation Solid-State Chemistry Grants DMR 87-17763 and DMR 87-14751 and by the Michigan State University Center for Fundamental Materials Research. I am indebted to the many graduate students and postdoctoral students named in the references for their dedication to and expertise in alkalide/electride synthesis and characterization. I acknowledge a Fellowship from the John Simon Guggenheim Foundation for partial support during the preparation of this manuscript. 


\section{References}

[1] For a comprehensive review and references to work before 1987 see Dye, J.L., and DeBacker, M.G., Annu. Rev. Phy. Chem. 38 (1987) 271.

[2] Dye, J.L., Science 247 (1990) 663.

[3] Solubilities are also moderately high $(\sim 0.5 \mathrm{M})$ in hamethyl phosphoric triamide (HMPA). See, for example, Gremmo, N., and Randles, J.E.B., Trans. Faraday Soc. I, 70 (1974) 1480.

[4] Dye, J.L., DeBacker, M.G., and Nicely, V.A., J. Am. Chem. Soc. 92 (1970) 5226.

[5] Dye, J.L., Lok, M.T., Tehan, F.J., Coolen, R. B., Papadakis, N., Ceraso, J.M., and DeBacker, M.G., Ber. Bunsen-Ges. Phys. Chem. 75 (1971) 659.

[6] Dye, J.L., in Electrons in Fluids, Jortner, J., and Kestner, N.R., Eds., (SpringerVerlag, Berlin-Heidelberg-New York, 1973) 77.

[7] Dye, J.L., Sankuer, R.F., and Smith, G.E., J. Am. Chem. Soc., 82 (1960) 4797.

[8] Dye, J.L., in Metal-Ammonia Solutions, IUPAC Supplement, Proceedings of an International Conference on the Nature of Metal Ammonia Solutions. Colloque Weyl II, Lagowski, J.J., and Sienko, M.J., Eds. (Butterworths, London, 1970) 1.

[9]. Vos, K.D., and Dye, J.L., J. Chem. Phys. 38 (1963) 2033.

[10] Bar-Eli, K., and Tuttle, T.R., Jr., J. Chem. Phys. 40 (1964) 2508.

[11] Dye, J.L., and Dalton, L.R., J. Phys. Chem. 71. (1967) 184.

[12] Dalton, L.R., Rynbrandt, J.D., Hansen, E.M., and Dye, J.L., J. Chem. Phys. 44 (1966) 3969.

[13] Dye, J.L., Pure Appl. Chem. 49 (1977) 3.

[14] For a summary, see Harris, R.L., and Lagowski, J.J., J. Phys. Chem. 85 (1981) 856.

[15] Golden, S., Guttman, C., and Tuttle, T.R., Jr., J. Am. Chem. Soc. 87 (1965) 135.

[16] Golden, S., Guttman, C., and Tuttle, T.R., Jr., J. Chem. Phys. 44 (1966) 3791.

[17] Matalon, S., Golden, S., and Ottolenghi M., J. Phys. Chem. 73 (1969) 3098.

[18] Ceraso, J.M., and Dye, J.L., J. Chem. Phys. 61 (1974) 1585.

[19] Dye, J.L., Andrews, C.W., and Ceraso, J.M., J. Phys. Chem. 79 (1975) 3076.

[20] For a discussion of the evidence for M-, see Dye, J.L., Prog. Inorg. Chem. 32 (1984) 327.

[21] Nakamura, Y., Horie, Y., and Shimoji, M., Trans. Faraday Soc.I 70 (1974) 1376

[22] Stacy, A.M., Johnson, D.C., Sienko, M.J., J. Chem. Phys. 76 (1982) 4248.

[23] Hagedorn, R., and Lelieur, J.-P., J. Phys. Chem. 84 (1980) 3652.

[24] Mott, N. F., Can. J. Phys. 34 (1956) 1356.

[25] Edwards, P.P., and Sienko, M.J., Acc. Chem. Res. 15 (1982) 87.

[26] Beckman, T.A., and Pitzer, K.S., J. Phys. Chem., 65 (1961) 1527.

[27] Dawes, S.B., Ward, D.L., Huang, R.H., and Dye, J.L., J. Am. Chem. Soc, 108 (1986) 3534.

[28] Ward, D.L., Huang, R.H., Kuchenmeister, M.E., and Dye, J.L., Acta Crystallogr. C46 (1990) 1831. 
[29] Dawes, S.B., Eglin, J.L., Moeggenborg, K.J., Kim, J., and Dye, J.L., J. Am. Chem. Soc. 113 (1991) 1605.

[30] Huang, R.H., unpublished results, this laboratory.

[31] Tehan, F.J., Barnett, B.L., and Dye, J.L., J. Am. Chem. Soc. 96 (1974) 7203.

[32] Huang, R.H., Ward, D.L., and Dye, J.L., Acta Crystallogr. C46 (1990) 1835.

[33] Dawes, S.B., Ward, D.L., Fussa-Rydel, O., Huang, R.H., and Dye,J.L., Inorg. Chem. 28 (1989) 2132.

[34] Ward. D.L., Huang, R.H., and Dye, J.L., Acta Crystallogr. C46 (1990) 1838.

[35] Huang, R.H., Ward, D.L., Kuchenmeister, M.E., and Dye, J.L., J. Am. Chem. Soc., 109 (1987) 5561.

[36] Huang, R.H., Faber. M.K., Moeggenborg, K.J., Ward, D.L., and Dye, J.L., Nature (London) 331 (1988) 599.

[37] Ward, D.L., Huang, R.H., and Dye, J.L., Acta Crystallogr. C44 (1988) 1374.

[38] Huang, R.H., Ward, D.L., and Dye, J.L., J. Am. Chem. Soc., 111 (1989) 5707.

[39] Kuchenmeister, M.E., and Dye, J.L., J. Am. Chem. Soc., 111 (1989) 935.

[40] Kuchenmeister, M.E., and Ward, D.L., unpublished results, this laboratory.

[41] Huang, R.H., Ward, D.L., and Dye, J.L., Acta Crystallogr. C46 (1990) 1835.

[42] Dye, J.L., Yemen, M.R., DaGue, M.G., and Lehn, J.-M., J. Chem. Phys. 68 (1978) 1665.

[43] Dague, M.G., Landers, J.S., Lewis, H.L., and Dye, J.L., Chem. Phys. Lett. 66 (1979) 169.

[44] Dye, J.L., DaGue, M.G., Yeman, M.R., Landers, J.S., and Lewis, H.L., J. Phys. Chem., 84 (1980) 1096.

[45] Ellaboudy, A.S, Dye, J.L., and Smith, P.B., J. Am. Chem. Soc., 105 (1983) 6490.

[46] Ellaboudy, A.S, Tinkham, M.L., Van Eck, B., Dye, J.L., and Smith, P.B., J. Phys. Chem. 88 (1984) 3852.

[47] Ellaboudy, A.S, and Dye, J.L., J. Magn. Reson. 66 (1986) 491.

[48] Dawes, S.B., Ellaboudy, A.S., and Dye, J.L., J. Am. Chem. Soc.109 (1987) 3508.

[49] Ward, D.L., Huang, R.H., Kuchenmeister, M.E., and Dye, J.L., Acta Crystallogr. C46 (1990) 1831.

[50] Tinkham, M.L., and Dye, J.L., J. Am. Chem. Soc. 107 (1985) 6129.

[51] Tinkham, M.L., Ellaboudy, A.S., Dye, J.L., and Smith, P.B., J. Phys. Chem. 90 (1986) 14.

[52] Rencsok, R., Kaplan, T.A., and Harrison, J.F., J. Chem. Phys. 93 (1990) 5875.

[53] Dye, J.L., in Valency. The Robert A. Welch Foundation Conference on Chemical Research XXXII. Houston, Texas, (1989) 65.

[54] Tientega, F., Dye, J.L., and Harrison, J.F., J. Am. Chem. Soc. 113 (1991) 3206.

[55] Issa, D., Ellaboudy, A.S., Janakiraman, R., and Dye, J.L., J. Phys. Chem. 88 (1984) 3847.

[56] Dye, J.L., and Ellaboudy, A.S., Chem. Br. 20 (1984) 210.

[57] Moeggenborg, K.J., Papaioannou, J., and Dye, J.L., Chem. of. Materials. 3 (1991) 514 
[58] Shin, D.-H., Ellaboudy, A.S., Dye, J.L., and DeBacker, M.G., J. Phys Chem. 1991 in press.

[59] Jaenicke, S., Faber, M.K., Dye, J.L., and Pratt, W.P., Jr. J. Solid State Chem. 68 (1987) 239.

[60] Skowyra, J.B., Dye, J.L., and Pratt, W.P., Jr., Rev. Sci. Instrum. 60 (1989) 2666.

[61] Hendrickson, J.E., unpublished results, this laboratory.

[62] Shin, D.-H., unpublished results, this laboratory.

[63] Landers, J.S., Dye, J.L., Stacy, A., and Sienko, M.J., J. Phys. Chem. 85 (1981) 1096.

[64 Huang, R.H., Faber, M.K., Wagner M.J., and Shin, D.H., unpublished work, this laboratory

[65] Ellaboudy, A.S., Bender, C.J., Kim, J., Shin, D.-H., Kuchenmeister, M.E., Babcock, G.T., and Dye, J.L., J. Am. Chem. Soc. 113 (1991) 2347.

[66] Ellaboudy, A.S., Holton, D.M., Edmonds, R.N., and Edwards, P.P., J. Chem. Soc. Chem. Commun. (1986) 1444.

[67] Ellaboudy, A.S., and Edwards, P.P., J. Am. Chem. Soc. 110 (1988) 1618.

[68] Holton, D.M., Ellaboudy, A.S., Edmonds, R.N., and Edwards, P.P., Proc. R. Soc. Lond. A415 (1988) 121.

[69] Concepcion, R., and Dye, J.L., J. Am. Chem. Soc. 109 (1987) 7203.

[70] Issa, D., and Dye, J.L., J. Am. Chem. Soc. 104 (1982) 3781.

[71] Faber, M.K., Fussa-Rydel, O., Skowyra, J.B., McMills, L.E.H., and Dye, J.L., J. Am. Chem. Soc. 111 (1989) 5957.

[72] DeBacker, M.G., Concepcion, R., Kim, J., Eglin, J.L., Guadagnini, R., and Huang, R.H., unpublished results, this laboratory.

[73] Herzfeld, K.F., Phys. Rev. 29 (1927) 701.

[74] Rao, C.N.R., and Edwards, P.P., Proc. Indian Acad. Sci. (Chem. Sci.) 96 (1986) 473.

[75] Wayda, A.L., and Dye, J.L., J. Chem. Educ. 62 (1985) 356.

[76] Wayda, A.L., Bianconi, P.A., and Dye, J.L., in Experimental Organometallic Chemistry, Wayda, A.L., and Darensbourg, M.Y., Eds., (American Chemical Society Symposium) 357 (1987) 116.

[77] Tsai, K.L., and Dye, J.L., J. Am. Chem. Soc. 113 (1991) 1650. 